\title{
ABUSO SEXUAL INFANTIL: ASPECTOS HISTÓRICOS, LEGAIS E OS PREJUÍZOS PARA O DESENVOLVIMENTO INFANTIL
}

\section{ARTIGO DE REVISÃo}

GONÇALVES, Natamy de Almeida ${ }^{1}$, DIAS, Camila Santos²

GONÇALVES, Natamy de Almeida. DIAS, Camila Santos. Abuso sexual infantil: aspectos históricos, legais e os prejuízos para o desenvolvimento infantil. Revista Científica Multidisciplinar Núcleo do Conhecimento. Ano 06, Ed. 09, Vol. 01, pp. 183-208. Setembro de 2021. ISSN: 2448-0959, Link de acesso: https://www.nucleodoconhecimento.com.br/psicologia/aspectos-historicos, DOI: 10.32749/nucleodoconhecimento.com.br/psicologia/aspectos-historicos

\section{RESUMO}

Por se tratar se uma violência que assola diversas crianças e adolescentes no mundo ao longo de toda a história, o abuso sexual infantil exige uma atenção minuciosa, considerando que é um fenômeno complexo e, em muitos casos, difícil de ser identificado, sendo o abusador geralmente uma pessoa de confiança da família e de quem se espera que cuide da vítima, como pais biológicos, padrastos, tios ou amigos muito próximos, por exemplo. Além disso, a maior parte dos casos de abuso sexual acontece na casa da própria vítima, local em que pouco se espera que a criança e o adolescente estejam em uma situação de vulnerabilidade. Com base nos fatores descritos, a presente pesquisa apresenta a seguinte questão norteadora: o que é abuso sexual e quais seus impactos no desenvolvimento infantil? Este artigo teve, então, como objetivo fazer uma revisão dos aspectos históricos e legais do abuso sexual, explorando as complexidades sobre suas definições e apresentando

\footnotetext{
${ }^{1}$ Pós-graduada em Neuropsicologia pela Faculdade de Tecnologia, Ciências e Educação - FATECE, pós-graduada em Psicologia Organizacional e do Trabalho na Fundação Hermínio Ometto e graduada em Psicologia pela mesma instituição.

2 Orientadora. Mestre em Psicologia como Ciência e Profissão (PUCCamp), Especialista em Educação e Psicopedagogia (PUCCamp), Especialista em Neuropsicologia (Instituto Hospital Israelita Albert Einstein), Graduada em Psicologia (Fundação Hermínio Ometto - FHO).
}

RC: 96433

Disponível em: https://www.nucleodoconhecimento.com.br/psicologia/aspectoshistoricos 
os possíveis efeitos provocados na vítima. Para isso foi feita uma revisão bibliográfica de caráter qualitativo, descritivo e exploratório, suscitando reflexões sobre o tema. Viu-se que a criança e o adolescente nem sempre tiveram amparo legal, tendo sofrido diversas violências sem que houvesse a devida punição a seus agressores. Ao longo do tempo, leis foram sendo instituídas e, no Brasil, o Estatuto da Criança e do Adolescente (ECA) marcara um tempo de determinação de direitos da infância e da adolescência, estabelecendo mecanismos de proteção, inclusive contra violências como o abuso sexual. Finalmente, considerou-se neste estudo que há a falta de informações à população sobre o tema, o que corrobora para a reprodução do mencionado delito. Observou-se que, considerando os prejuízos à saúde biopsicossocial da vítima e de sua família, estudos e projetos de prevenção foram feitos, como também instituídas diferentes formas de denúncia desse crime. Concluiu-se que é necessário que haja estratégias para preparar as famílias, profissionais e instituições responsáveis pela garantia de direitos da criança e do adolescente para que possam contribuir com o fortalecimento do combate contra o abuso sexual.

Palavras-chave: Abuso Sexual, Violação Sexual Infantil, Criança e Adolescente.

\section{INTRODUÇÃO}

Se tratando de um assunto presente em diferentes partes do mundo e em diversos períodos históricos, o abuso sexual permanece na atualidade e é um tema importante a ser tratado, visto que tal violência tem sido continuamente reproduzida. Waiselfisz (2012) mostra que, de acordo com os registros do Sistema de Informações de Agravos de Notificação (SINAN), em 2011 foram atendidas 10.425 crianças vítimas de abuso sexual no Brasil. Já em 2018, o Brasil registrou ao menos 32 mil casos de abuso sexual contra crianças e adolescentes em 2018, o maior índice de notificações já registrado pelo Ministério da Saúde. Desde 2011, os agentes de saúde passaram a ter a obrigação de computar atendimentos. De lá para cá, os números crescem ano a ano, e somam um total de 177,3 mil notificações em todo o país[3]. Entretanto, como denotam Aded et al. (2006), acredita-se que os 
casos identificados ou denunciados não dizem sobre a realidade do número de casos. Um dos motivos é que, na maioria dos casos, o agressor é muito próximo ou faz parte da família da vítima; outro fator é a própria falta de identificação dos casos, ou mesmo a crença de que não exista como provar o ato do abuso, entendendo como prova concreta apenas o exame médico. Assim, acredita-se que o número de casos é bem maior que o estimado.

Com base nos fatores descritos, a presente pesquisa apresenta a seguinte questão norteadora: o que é abuso sexual e quais seus impactos no desenvolvimento infantil? Este artigo teve, então, como objetivo fazer uma revisão dos aspectos históricos e legais do abuso sexual, explorando as complexidades sobre suas definições e apresentando os possíveis efeitos provocados na vítima.

Trata-se de uma revisão bibliográfica de caráter qualitativo, descritivo e exploratório, para a qual foram utilizados livros como fonte de dados, além de artigos científicos que foram encontrados no site de buscas Google. Alguns sites que apresentam dados importantes sobre o tema também foram utilizados nesta pesquisa.

Considerando que o abuso sexual é uma violência que acontece de maneiras que geralmente dificultam sua identificação, além de provocar muitas dúvidas de como lidar com ela, há a necessidade de que mais pesquisas sejam desenvolvidas para que se tenha cada vez mais conhecimento dos mecanismos que envolvem este delito e, com isso, mais estratégias de combate sejam estabelecidas. Deste modo, a presente pesquisa evidencia sua relevância social e científica, contribuindo para o esclarecimento sobre $o$ assunto e para que outras pesquisas sejam realizadas a partir desta.

\section{ABUSO SEXUAL: DEFINIÇÕES, HISTÓRIAS, LEIS}

O abuso sexual é um fenômeno social que necessita de atenção refinada por se tratar de um assunto complexo, que envolve diferentes problemáticas e que gera sofrimento a muitas crianças, adolescentes e famílias, sendo este um dentre os 
diversos tipos de violência. Considerando as várias definições de abuso sexual, pode-se destacar a dada pelo Ministério da Saúde (BRASIL, 2002, p.13):

\begin{abstract}
Abuso sexual - consiste em todo ato ou jogo sexual, relação heterossexual ou homossexual cujo agressor está em estágio de desenvolvimento psicossexual mais adiantado que a criança ou o adolescente. Tem por intenção estimulá-la sexualmente ou utilizá-la para obter satisfação sexual. Apresenta-se sobre a forma de práticas eróticas e sexuais impostas à criança ou ao adolescente pela violência física, ameaças ou indução de sua vontade. Esse fenômeno violento pode variar desde atos em que não se produz o contato sexual (voyerismo, exibicionismo, produção de fotos), até diferentes tipos de ações que incluem contato sexual sem ou com penetração. Engloba ainda a situação de exploração sexual visando lucros como é o caso da prostituição e da pornografia.
\end{abstract}

Assim, sendo considerado como um ato de violência, o abuso sexual pode ser cometido de diversas formas, desde aqueles em que não há contato físico do agressor com a criança ou adolescente como, por exemplo, o voyeurismo em que ocorre a observação da nudez da vítima para a obtenção de satisfação sexual, e o exibicionismo, em que o agressor exibe os próprios órgãos sexuais. Pode também ocorrer por meio da exibição vídeos e revistas pornográficas para a vítima, despertando sua sexualidade de forma precoce e deturpada; dando dinheiro, doces ou presentes para que a criança ou adolescente permita que o agressor abuse de seu corpo; violentando-a com sexo oral, que também é um meio de transmissão de Doenças Sexualmente Transmissíveis (DST); ou mesmo mantendo relações sexuais tanto vaginais quanto anais. Ele pode ocorrer até mesmo sem que a vítima se dê conta, ou ao ponto de ocasionar lesões físicas, e o adoecimento psicológico. Além disso, tal abuso não é apenas cometido por adultos homens sobre crianças: ele pode ser perpetrado por adolescentes, mulheres, idosos e por diferentes pessoas em diferentes circunstâncias. Essa variação de maneiras em que o abuso sexual pode ocorrer pode ocasionar uma dificuldade de identificação de alguns tipos que, muitas vezes, não são reconhecidos por adultos como tal (BRASIL, 2002).

Ademais, como pontuado pelo Ministério da Saúde (BRASIL, 2002), o abuso sexual engloba a exploração sexual, que é quando envolve dinheiro, presentes, ou algo do gênero, em uma comercialização do corpo da criança e/ou do adolescente, como 
nos exemplos mencionados, que são a prostituição e a pornografia. Entretanto, como apontam Vega e Paludo (2015, p.48), "definir a exploração sexual tem sido uma árdua tarefa, inclusive para a área acadêmica". Faleiros e Campos (2000), em uma análise do vocabulário do tema, identificaram uma imprecisão terminológica. As autoras dão um exemplo: o abuso sexual foi estabelecido como crime sexual, vitimização sexual, sevícia sexual, agressão sexual, violência sexual, exploração sexual, maus tratos, ultraje sexual e injúria sexual. Tratando-se de nomear a violência intrafamiliar, foram encontrados os termos: incesto, abuso sexual incestuoso, violência sexual doméstica, abuso sexual doméstico.

O uso sexual de menores de idade com fins lucrativos é designado ora como prostituição infanto-juvenil, ora como abuso sexual, ora como exploração sexual comercial. Por outro lado, um mesmo termo pode designar distintas realidades, como, por exemplo, o termo exploração sexual é utilizado pela OMS para designar situações de abuso sexual intra e extrafamiliar e prostituição, enquanto muitos autores o utilizam referindo-se apenas à exploração sexual comercial (FALEIROS; CAMPOS, 2000, p.4).

Deste modo, há ainda divergências entre autores com relação ao vocabulário apropriado para cada situação. Não obstante, para Faleiros e Campos (2000), o uso de termos diferentes como sinônimos e como se equivalessem a um mesmo conceito, não se trata apenas de terminologia, e sim de uma questão de âmbito epistemológico, isto é, denuncia a falta da conceituação da problemática. Esta indefinição teórica e conceitual deve-se à complexidade e diversidade, bem como ao fato de que o desvelamento, a consciência e o enfrentamento desta problemática são ainda recentes, bem como a preocupação com a infância, como se verá a adiante.

Além de ocorrer de diferentes maneiras, o abuso sexual infantil é oriundo de diferentes lugares do planeta e descrito desde a antiguidade, como mostram Aded et al. (2006). Entretanto o avanço com relação à prevenção e amenização das consequências foi pouco. O que talvez dificulte o enfrentamento do problema é o fato de perpassar complexidades culturais, religiosas, legais e profissionais de todo o mundo. 
Oliveira (2006) aponta que ao longo da história, uma das características que marcaram a cultura humana foi a negligência contra a criança e o adolescente, já que não se possuía ideia de fragilidade como característica da infância, e esta questão era pouco discutida, assim como não existiam políticas de proteção.

A autora apresenta vários pontos da história que exemplificam essa negligência, denotando que em muitos povos da antiguidade, o abuso sexual infantil era tido como normal e, além disso, muitos desses povos não faziam distinção entre a criança e o adulto, como em Esparta, por exemplo. Afirma ainda que no Ocidente, durante a idade média, esta distinção também não era feita, e a criança permanecia exposta a diferentes tipos de punições; "[...] logo que estivesse sem a necessidade dos cuidados maternos básicos, era vista como um adulto e desta forma crescia" (OLIVEIRA, 2006, p. 11). Assim, a criança muito nova não era considerada como um ser humano e a taxa de mortalidade era alta, fato este compreendido como um fenômeno corriqueiro.

Azambuja (2006, p.3) apresenta que somente no final do século XVII é que a criança passa a ter uma distinção da pessoa adulta. Até este momento, as escolas não eram organizadas por idade, sendo frequentadas por crianças e adultos no mesmo local. Para a autora, "[...] com o surgimento do entendimento de que a infância é uma fase distinta da vida adulta, os castigos, a punição física, os espancamentos através de chicotes, paus e ferros passam a ser utilizados como instrumentos necessários à educação" (AZAMBUJA, 2006, p.3). Em 1780, na Inglaterra, os pais poderiam condenar as crianças à pena de enforcamento, sob mais de duzentos tipos penais. Em Nova York, em 1871, uma menina sofreu sérios maus tratos e, como não havia local para tal tipo de denúncia, o caso da menina Mary Ellen acabou por ser encaminhado para a Sociedade Para a Prevenção da Crueldade Contra os Animais, para que pudesse ser investigado pelo tribunal. $O$ caso, que ocasionou muita indignação da população, foi o que incitou a fundação de uma sociedade voltada à proteção da criança. 
De acordo com Azambuja (2006), com relação ao Brasil, as primeiras embarcações lançadas ao mar por Portugal, eram compostas por homens e crianças órfãs do rei, que prestavam serviços durante a viagem e eram submetidas a abusos sexuais da parte dos marujos. Ela conta que, caso ocorresse tempestades, as crianças eram as primeiras "cargas" a serem jogadas ao mar.

Guerra et al. (2013) aponta que até o começo do século XX, o Estado não se ocupava de desenvolver políticas sociais direcionadas para a criança e o adolescente. Deste modo, a Igreja Católica era quem desenvolvia importantes ações de cuidado a crianças e adolescentes ditos "abandonados". As Santas Casas de Misericórdia não cuidavam apenas de doentes e enfermos, mas também de crianças cujos direitos haviam sido violados. Assim, na tentativa de diminuir a quantidade de bebês concebidos fora do casamento e que eram abandonados até nas ruas, devido pressões sociais da época, a Igreja Católica criou a Roda dos Expostos. Tratava-se de um dispositivo cilíndrico em que a criança era colocada e deixada, de maneira a garantir o anonimato de quem cometia o abandono.

No final da Primeira Guerra Mundial, organizações internacionais recém-construídas passaram a articular códigos dos direitos humanos. Novos organismos começaram a dar atenção aos direitos da criança especificamente. A Agência Internacional do Trabalho então recém-criada (hoje Organização) voltou suas convenções para a garantia dos direitos das crianças trabalhadoras, assim como em 1919, na Convenção referente ao Trabalho Noturno dos Adolescentes (Indústria); também em 1921, a Convenção sobre Idade Mínima (Agricultura). Entretanto, a maioria da legislação produzida entre as duas guerras mundiais não explicitou a especificidade do direito da criança e do adolescente como sendo distintos dos diretos dos adultos (UNICEF, 2009).

A primeira definição de direitos formais da criança, que foi criada pelas organizações internacionais nascentes, originou-se do trabalho de Eglantyne Jebb que fundou na Inglaterra, em 1919, o Save the Children, e estabeleceu em Genebra, no ano posterior, União Save the Children Internacional, para levantar recursos em ajuda 
emergencial às crianças que sofriam em decorrência da Primeira Guerra Mundial. Jebb, em 1923, declarou sua posição com relação aos direitos da criança: "[...] Acredito que devemos reclamar certos direitos para a criança e trabalhar para que sejam reconhecidos internacionalmente" (UNICEF, 2009, p.4). Assim, a União Save the Children Internacional criou a proposta preliminar de uma declaração que reivindicava direitos específicos à população infantil e fez com que, em 26 de setembro de 1924, a Liga das Nações a adotasse na Declaração de Genebra dos Direitos da Criança.

Assim, a Declaração de Genebra discutia cinco princípios básicos: o direito a condições para o desenvolvimento material e espiritual; o direito à prioridade no aliviamento em situações de risco; direito à ajuda em circunstância de fome, incapacitação, doença, delinquência ou orfandade; direito a uma formação que oriente a criança para a vida em sociedade; e direito à proteção contra a exploração (UNICEF, 2009).

Segundo o Fundo das Nações Unidas para a Infância (UNICEF, 2009), a Segunda Guerra Mundial corroborou para a criação da Organização das Nações Unidas (ONU). A fusão entre Associação Internacional para o Bem-estar da Criança, estabelecida em Bruxelas e a União Save the Children Internacional, resultou na União Internacional para o Bem-estar da Criança (International Union for Child Welfare - IUCW), que levou a Organização das Nações Unidas a endossar a Declaração de Genebra.

O site Portal Brasil[4] mostra que em 1927, o país promulgou o primeiro Código de Menores. Na época, casos de grande repercussão pública incitaram o então presidente Washington Luís a determinar que 18 anos fosse idade mínima para prisão de infratores. O ocorrido com o menino Bernardino, de 12 anos, foi um desses casos. Em 1926, o menino, que era engraxate, se irritou com um cliente devido à sua recusa de pagar pelo serviço prestado nas ruas do Rio de Janeiro. A criança teria atirado tinta neste sujeito e, por isso, acabou sendo presa por quatro semanas. 
Bernardino foi violentado na cela por 20 adultos, o que ocasionou indignação dos médicos quando o menino foi para a Santa Casa.

Assim, a propagação do caso ocasionou uma polêmica forte, iniciando uma discussão pública que alcançou as rodas do Congresso, como também do Palácio do Catete, onde era a sede do governo federal. Então o presidente escolheu o dia 12 de outubro (Dia das Crianças) para assinar o Código de Menores, que foi a primeira legislação no país para a infância e adolescência especificamente. Um artigo deste código proibiu a Roda dos Expostos. "Com o código, a mãe teria que registrar a criança e assim entregá-la a um orfanato" (BRASIL, s/d).

O site da Declaração Universal dos Direitos Humanos[5] (DUDH) mostra que no dia 10 de dezembro de 1948, em Paris, tal Declaração, foi proclamada pela Assembleia Geral das Nações, através da Resolução 217 A (III). Trata-se de um documento que marcou a história dos direitos humanos. A DUDH foi elaborada por diferentes representantes de várias origens jurídicas e culturais de todo o mundo, sendo então uma norma comum de modo que alcance a todos os povos e nações. Esta declaração surge com a visão de que o homem tem direito a uma vida digna: "Considerando que o reconhecimento da dignidade inerente a todos os membros da família humana e de seus direitos iguais e inalienáveis é o fundamento da liberdade, da justiça e da paz no mundo [...]" (DUDH, 1948).

Nesta ocasião, a ONU estava mais empenhada em discutir princípios da DUDH, porém a própria IUCW defendia a ideia de um novo documento, que fosse específico dos direitos da criança, atualizando a declaração anterior, e reiterando o princípio de que a criança deve receber o que a humanidade tenha de melhor a oferecer. A Declaração dos Direitos da Criança só foi adotada pela ONU em 20 de novembro de 1959. O endosso da Assembleia Geral foi importante, já que evidenciou a necessidade de que os direitos da criança fossem considerados separadamente. A Declaração dos Direitos da Criança salientou o bem-estar emocional da criança, e garantiu seu direito de ser priorizada em receber proteção em emergências. "Apesar dessas mudanças, o documento de 1959 manteve uma abordagem assistencialista, 
visando salvar, guardar e proteger a criança, dando pouca importância ao aumento de seu poder" (UNICEF, 2009, p.5).

Inoue e Ristum (2008) denotam que a violência tem sido a principal causa de mortes principalmente no público jovem e infantil. Nos Estados Unidos, apenas em 1960 é que a violência contra crianças torna a ser vista como um problema médico-social. "[...] especialmente os pediatras passaram a tratar do tema mostrando as sequelas dos maus-tratos e as discrepâncias entre as evidências radiológicas sobre as lesões e as explicações dos agressores" (MINAYO, 2002, p. 109). Apesar de esse movimento no interior da medicina ter provocado críticas e acusação de "medicalização da violência", ele tivera uma grande influência na produção teórica, desencadeando pesquisas, bem como nos movimentos a favor da defesa dos direitos infanto-juvenis. Assim, o campo médico iniciou uma repulsa social sobre o abuso sexual, que tomou consistência também a partir dos Estados Unidos, ao lado fortalecimento do movimento feminista de 1970.

O ano de 1973 foi marcado por um acontecimento que fez de 18 de maio, um dia importante no calendário do Ministério da Saúde, memorado até os dias atuais. O fato é que, nesta data, Araceli Cabrera Crespo, de nove anos incompletos, desapareceu da escola onde estudava, não mais sendo vista com vida. O site do Conselho Nacional de Saúde explica que "Araceli foi espancada, estuprada, drogada e morta numa orgia de drogas e sexo. Seu corpo, o rosto principalmente, foi desfigurado com ácido" (BRASIL, s/d). Depois de seis dias do ocorrido, o corpo foi encontrado em um terreno baldio, nas proximidades do centro da cidade de Vitória, Espírito Santo. Tal martírio teve grande significado, de modo que esta data é considerada e lembrada como o Dia Nacional de Combate ao Abuso e Exploração Sexual de Crianças e Adolescentes.

Entre as décadas de 1960 e 1970, mobilização em prol dos direitos da criança e do adolescente foi feita por organizações não governamentais (ONGs), que incitaram grandes avanços; deste modo, estas organizações impeliram as Nações Unidas a declarar o ano de 1979 como o Ano Internacional da Criança, na proposta de 
chamar atenção para problemática que envolve a infância. "Uma vez estabelecido esse acordo, o governo da Polônia submeteu à Comissão de Direitos Humanos da ONU um texto preliminar de convenção sobre os direitos da criança" (UNICEF, 2009, p.5). Assim, ficou evidenciado que a finalização desse documento demandaria melhor preparação e mais tempo. Deste modo, o processo estendeu-se por uma década, considerando que a redação de um tratado envolvendo diversas áreas de interpretação cultural e social é um trabalho que demanda cautela.

Minayo (2002) conta que na década de 1980, no campo da saúde pública mundial, é que a violência se apresenta como uma questão substantiva. Os movimentos de atenção especializada e prevenção surgem a partir do reconhecimento da morbimortalidade por meio de violência, como um problema sério para a saúde em seus aspectos sociais, bem como alvo de atenção primária, secundária e terciária. Também em 1980, no Brasil começam a se pensar em propostas, no ritmo do movimento social que corroborou para a Constituição de 1988. Somente neste ano é que a criança passa a ser considerada sujeito de direitos, graças à Constituição Federal, passando a contar com a Convenção das Nações Unidas, em uma nova época de defesa de direitos da criança e do adolescente.

Há três anos antes desta constituição, em 4 de julho de 1985, o Centro Regional de Atenção aos Maus Tratos na Infância (CRAMI), foi fundado por um grupo composto por diferentes profissionais pertencentes à Pontifícia Universidade Católica de Campinas (PUC-Campinas), tendo envolvidos representantes de vários setores da comunidade, como a Ordem dos Advogados do Brasil (OAB) - Campinas, Juizado de Menores, entre outros. Segundo o site do próprio CRAMI[6], "Preocupados com os casos rotineiros de crianças que chegavam aos órgãos públicos, apresentando marcas de espancamentos, queimaduras, escoriações, hemorragias internas, esse grupo fundou o CRAMl". Muitas dessas crianças chegavam a óbito, e os responsáveis justificavam como queda ou falta de atenção da própria criança. Ao longo do tempo, foi construído um protocolo de atendimento a casos de violência doméstica. A partir da constatação do caso, colhiam-se dados e a assistente social dava procedimento ao atendimento no lar das vítimas, visando ter contato com a real 
situação e, dependendo da gravidade do caso, encaminhar a vítima à Vara da Infância.

O Site do CRAMI informa ainda que "o trabalho desenvolvido pelos profissionais altamente capacitados do CRAMI começou a se tornar referência e incentivou a abertura de outros CRAMls no estado de São Paulo". Por determinação do Sistema Único de Assistência Social (SUAS), em 2014 o CRAMI estendeu seu atendimento a toda pessoa em situação de vulnerabilidade e risco social, não sendo mais restrito ao atendimento a crianças e adolescentes vítimas de violência doméstica. Trata-se de uma entidade não governamental, sem fins lucrativos, e conta com atendimento de psicólogos, assistentes sociais, e educadores sociais, que segue com a missão, segundo o site, de "Construir um futuro melhor para crianças, adolescentes e vulneráveis vítimas de violência doméstica".

No dia 20 de novembro de 1989, a Assembleia Geral da ONU adotou a Convenção sobre os Direitos da Criança, entrando em vigor no dia 2 de setembro de 1990. Este é o mais abrangente de todos os tratados de direitos humanos e instrumentos legais em prol da proteção dos direitos da criança. Apesar de existirem dispositivos em defesa dos diretos da criança em equipamentos internacionais de direitos humanos, a Convenção é o primeiro a abranger e articular todos os aspectos relevantes de direitos importantes para a criança, sendo eles econômicos, culturais, políticos e sociais. Ainda, foi o primeiro equipamento internacional que reconheceu explicitamente que a criança é um ator social possuidor de direitos próprios (UNICEF, 2009).

Segundo a UNICEF (2009, p. 2), "Mediante os dispositivos do tratado, os Estados Partes estão obrigados por lei a atender os direitos de todas as crianças". A Convenção prevê 54 artigos e fundamenta-se em quatro princípios básicos: o melhor interesse da criança; a não discriminação; o respeito pelas opiniões da criança; e o direito à sobrevivência e ao desenvolvimento. O amplo objetivo que possui e a importância que dá à representação que favorece a criança determinam a pertinência incessante de todas as ações que visam atender aos direitos da criança. 
"A Convenção reafirma e enriquece os direitos humanos de maneira significativa" (UNICEF, 2009, p. 2). Reitera-os aplicando de forma direta a criança muitos dos princípios essenciais de documentos internacionais de direitos humanos que preexistiram, como a não discriminação e a universalidade; fortalece-os ao estabelecer e expandir dispositivos inclusos em outros equipamentos dos direitos humanos, esclarecendo as responsabilidades dos Estados Partes em relação à criança. Integra direitos da criança que não estavam incorporados de maneira ampla. Enfatiza que a responsabilidade pela realização dos direitos da criança deve ser atribuída a quem compete deveres referentes a ela, como a família e as pessoas responsáveis pela criança e os Estados Partes.

A convenção tem um significado que vai além de suas implicações legais. $O$ instrumento contribuiu também para que houvesse uma transformação nas atitudes em relação à infância. Deveras, a Convenção determinou os termos da infância, configurando os padrões mínimos para os cuidados, tratamento, a sobrevivência, a proteção, a participação e o desenvolvimento, que são direitos de todos os indivíduos cuja idade é menor de 18 anos. Seus artigos reafirmam que é preciso proteger a infância como período diferente da vida adulta e estabelecer um tempo durante o qual a criança cresça, aprenda, brinque e desenvolva-se, para que então os direitos da criança sejam plenamente realizados (UNICEF, 2009).

Como mostra Lemos (2008), inaugurando uma nova perspectiva de direitos e deveres pautados na doutrina de proteção integral, o Estatuto da Criança e do Adolescente (ECA), foi promulgado em 1990, como Lei Federal n. 8.069/90, garantindo à criança e ao adolescente o respeito enquanto pessoas em desenvolvimento particular:

Art. $3^{\circ}$ A criança e o adolescente gozam de todos os direitos fundamentais inerentes à pessoa humana, sem prejuízo da proteção integral de que trata esta Lei, assegurando-se lhes, por lei ou por outros meios, todas as oportunidades e facilidades, a fim de lhes facultar o desenvolvimento físico, mental, moral, espiritual e social, em condições de liberdade e de dignidade (BRASIL, 1990). 
Esta lei põe em cena um novo diagrama, estabelecendo práticas diferentes em alguns aspectos das previstas nos Códigos de Menores de 1927 e 1979. "Se, no Código de Menores, o objeto era o menor; no Estatuto da Criança e do Adolescente, o objeto é a criança e o adolescente enquanto sujeitos de direitos" (LEMOS, 2008, p.98). Deste modo, inaugura-se uma nova identidade social denominada crianças e adolescentes. Não são somente as práticas que mudaram, bem como o objeto é outro.

O ECA vem com uma proposta de construção de um modelo de proteção integral a crianças e a adolescentes, não estando restrito apenas à atenção após os direitos serem violados, mas antes que a violação aconteça, como está previsto em seu Art. 70: "É dever de todos prevenir a ocorrência de ameaça ou violação dos direitos da criança e do adolescente" (BRASIL, 1990). Esta lei federal assegura, dentre outros aspectos, a proteção da criança contra qualquer tipo de violência, inclusive a sexual.

Sabe-se que, na maioria dos casos, o abusador tem uma proximidade com a família. Como mostram Santos, Costa e Granjeiro (2009), a maioria dos casos de abusos sexuais ocorre no seio familiar, e em primeiro lugar praticados pelos pais biológicos das vítimas e, em segundo, pelos padrastos. Este é um exemplo de Violência Intrafamiliar que, de acordo com Araújo (2002), trata-se da violência que acontece na família, envolvendo pessoas que residem ou não no mesmo local, mas que não é restrita somente à família, e sim, envolve sujeitos de comum convívio no mesmo espaço doméstico, tendo ou não laços parentescos. Para estes casos, o ECA possui especificidades e uma delas é mencionada no Art. 101:

$\S 2^{\circ}$ Sem prejuízo da tomada de medidas emergenciais para proteção de vítimas de violência ou abuso sexual e das providências a que alude o art. 130 desta Lei, o afastamento da criança ou adolescente do convívio familiar é de competência exclusiva da autoridade judiciária e importará na deflagração, a pedido do Ministério Público ou de quem tenha legítimo interesse, de procedimento judicial contencioso, no qual se garanta aos pais ou ao responsável legal o exercício do contraditório e da ampla defesa (BRASIL, 1990).

RC: 96433

Disponível em: https://www.nucleodoconhecimento.com.br/psicologia/aspectoshistoricos 
Estas leis de proteção da criança e do adolescente contra o abuso sexual são extremamente necessárias, já que trata de algo grave e que pode acarretar muitos malefícios à vítima, como será apontado a seguir.

\subsection{OS DANOS À VÍTIMA E POSSÍVEIS AÇÕES}

Dentre as consequências que o abuso sexual pode provocar à criança e ao adolescente, pode-se destacar: prejuízos cognitivos, comportamentais, emocionais e sociais; isolamento social, medo exagerado, dificuldades de se ajustar, ideias homicidas e suicidas, déficit de linguagem a aprendizagem, perda de interesse pelas brincadeiras e pelos estudos, fugas de casa, automutilação, isolamento social, agressividade e outras consequências que podem comprometer seriamente a vida da vítima (SERAFIM et al., 2011).

Prado e Carneiro (2005) discorrem, sob a perspectiva da psicanálise, a respeito do trauma que, segundo eles, o referido termo enfatizaria o estrago gerado na capacidade de simbolizar e transformar, bem como a corroboração de zonas psíquicas mortas, que interferirão em gerações futuras, atingindo suas escolhas amorosas e sua perspectiva de lograr de sua sexualidade. As autoras discutem a partir de dois tipos de traumas, propondo chamá-los de ativo e cumulativo, sendo que o primeiro permanece no psiquismo da pessoa repetidamente, principalmente quando se trata de abuso sexual infantil, podendo ter as diversas manifestações, como promiscuidade, atuações, quadros psicopáticos, depressões, quadros psicossomáticos etc.

Já o trauma cumulativo refere-se à tensão recorrente do não cumprimento do papel de mãe como escudo protetor, que parte na fase de desenvolvimento que o bebê precisa da mãe exercendo seu papel; esses fracassos maternos podem ser passíveis de correção conforme o processo de maturação. Quanto ao trauma ativo, "da mesma forma que o trauma cumulativo, ele é traiçoeiro, só que em vez de agir e se fixar por toda a infância e adolescência, ele o faz por toda a vida, e além dela, já que se reedita através das gerações" (PRADO; CARNEIRO, 2005, p.31). Assim 
sendo, o trauma pode interferir e ocasionar sofrimento durante a vida inteira da vítima, trazendo diversas possibilidades de efeitos graves em longo prazo.

A relação da criança com adultos abusivos, tendo como consequência a quebra da confiança e a insegurança, favorece a vítima a não acreditar mais na confiabilidade e na segurança das pessoas de forma geral, o que pode refletir em suas relações futuras. Assim, a partir da adolescência, há caso de vítimas que, no desespero por obtenção de afeto, acabam por tornarem-se promíscuas; em contrapartida, outras raramente se disponibilizam para relacionamentos; ambos os casos seguem em direção ao isolamento e à depressão (PRADO; CARNEIRO, 2005).

Padilha (2002) fala da peculiaridade do abuso sexual, apontando que muitas vezes não existem provas físicas da consumação do mesmo e então o agressor argumenta que não forçou a criança a nada. "Considerar esta característica do fenômeno parece ser fundamental no planejamento de intervenções para prevenção ou tratamento de situações de abuso sexual, intrafamiliar ou extrafamiliar" (PADILHA, 2002, p. 210). Assim, a prevenção de tal violência exige um conhecimento dos movimentos que perpassam as agressões.

Como já mencionado, o Ministério da Saúde aponta que o abuso sexual "Apresentase sobre a forma de práticas eróticas e sexuais impostas à criança ou ao adolescente pela violência física, ameaças [...]”, mas completa: "[...] ou indução de sua vontade" (BRASIL, 2002, p.13). Então, de fato, a maioria dos casos de abuso sexual ocorre sob ameaças do agressor, à sombra de violências, chantagens etc., entretanto, induzir a vontade da vítima também se constitui como agressão.

Há ainda atualmente um conceito errôneo que julga que se a criança e principalmente o adolescente forem coniventes com o ato sexual, a situação não configuraria como um abuso. Entretanto, a lei brasileira não deixa dúvidas de que a criança e o adolescente são vulneráveis já que, como já trazido à presente pesquisa, se a pessoa estiver em um estágio de desenvolvimento psicossexual mais adiantado que a vítima, tratar-se-á de abuso sexual (BRASIL, 2002). 
Assim sendo, ainda que a criança ou o adolescente consinta ao ato sexual, isto é claramente condenável pela legislação brasileira. Abordando sobre os crimes sexuais contra vulnerável, o art. 217-A do Código Penal deixa claro que "Ter conjunção carnal ou praticar outro ato libidinoso com menor de 14 (catorze) anos: Pena - reclusão, de 8 (oito) a 15 (quinze) anos" (HARMS, 2016, p.577).

Além disso, em 06 de novembro de 2017 o Superior Tribunal de Justiça (STJ) lançou a súmula 593, que determina enfaticamente que é irrelevante para a caracterização do delito o consentimento ou não da vítima:

O crime de estupro de vulnerável se configura com a conjunção carnal ou prática de ato libidinoso com menor de 14 anos, sendo irrelevante eventual consentimento da vítima para a prática do ato, sua experiência sexual anterior ou existência de relacionamento amoroso com o agente. (Súmula 593, TERCEIRA SEÇÃO, julgado em 25/10/2017, DJe 06/11/2017) (BRASIL, 2017).

Desta forma, a legislação brasileira deixa ainda mais claro que perante a independentemente das circunstâncias de aceitação ou não da criança ou adolescente, os fatores citados sobre o abuso sexual se aplicam e são constituídos como crimes.

Além disso, o fato de a vítima consentir de alguma forma pode provocar um aumento no sentimento de culpa e agravar os prejuízos emocionais, além de corroborar para o seu silêncio sobre a violência vivida e, em muitos casos, favorecendo para que a criança ou adolescente continue sendo abusada sexualmente. Para Padilha (2002), a duração do abuso pode consistir em um episódio isolado ou de modo rotineiro com duração de vários anos sem a revelação a terceiros. A agressão pode ser feita com vítimas de qualquer idade, desde bebês ou crianças muito pequenas, até a adolescência.

Ainda, as hipóteses sobre o comportamento de conivência com tal violência se estabelecem de acordo com o comportamento da mãe, do pai ou padrasto, ou da criança, provenientes da história de vida, que por vezes repetem padrões de gerações passadas. A falta de um repertório de autoproteção pode ser advinda de 
modelos inadequados dos pais, que possivelmente não tenham tido um modelo adequado de seus pais, e assim, sucessivamente. "Este mecanismo de repetição intergeracional de comportamentos de exposição a risco explicaria por que as mães, pais ou padrastos tornam-se "cegos" com relação ao abuso sexual [...]" (PADILHA, 2002, p.211). Isto é, eles não conseguem identificar os indícios da violência.

Além disso, a fase de desenvolvimento em que a vítima se encontrar tem interferência tanto no processo de descoberta assim como no julgamento do suspeito: "O abuso infantil é um crime que, muitas vezes, só pode ser provado pelo testemunho de crianças pré-escolares. Se o testemunho de uma criança for incorreto, um adulto inocente pode ser punido injustamente" (PAPALIA; OLDS; FELDMAN, 2006, p. 301). Como bem apontam as autoras, a criança com pouca idade pode acabar por "recordar-se" de acontecimentos não ocorridos; elas tendem a ser sugestionáveis e sua fala pode ser induzida por outra pessoa, sendo difícil discriminar a falsidade da fala de uma criança que é entrevistada por alguém que faz perguntas com detalhes tendenciosos. Isto pode ocorrer principalmente com menores de quatro anos de idade, pois nesta fase as crianças são mais propensas a cometerem erros na recordação de detalhes de um acontecimento que varia com repetição. Não obstante, Habigzang, Ramos e Ekoller (2011) referem-se ao momento da revelação do abuso sexual como crucial na vida da vítima, já que pode ocasionar revitimizações caso os adultos não acreditem na fala da criança, e não tomem as devidas medidas de proteção, que deve contar com uma rede de apoio afetivo e social, que é composta por sistemas ou pessoas significativas para a vítima.

Nos casos de abuso sexual contra crianças e adolescentes compreende-se como constituinte da rede: família, escola, comunidade, Conselho Tutelar, Delegacia, Conselho de Direitos da Criança, Ministério Público e Juizado da Infância e Adolescência, abrigos, serviços de saúde (postos de saúde e hospitais) e assistência social (Centro de Referência da Assistência Social e Centro de Referência Especializado da Assistência Social) (HABIGZANG; RAMOS; KOLLER, 2011, p. 468).

Desse modo, todas essas instituições têm a responsabilidade de proteger a vítima, se empenhando para planejar e fazer intervenções que minimizem efetivamente os

RC: 96433

Disponível em: https://www.nucleodoconhecimento.com.br/psicologia/aspectoshistoricos 
efeitos da violência sofrida pela criança ou adolescente (HABIGZANG; RAMOS; KOLLER, 2011). A escola se destaca por se tratar de um ambiente presente em fases importantíssimas da vida de crianças e adolescentes em seu desenvolvimento.

Ainda esclarecendo sobre a implicação no desenvolvimento da vítima do abuso sexual, Papalia; Olds e Feldman (2006) mostram os citam mais comuns de acordo com a idade: na pré-escolar destaca-se a ansiedade, pesadelos e comportamento sexual inadequado; nas crianças em idade escolar observa-se comportamentos agressivos, problemas escolares, medo, hiperatividade, e até doença mental; por fim, adolescentes comumente apresentam quadros de depressão, queixas físicas, fuga, ações ilegais, comportamentos autodestrutivos ou suicidas, e abuso de substâncias químicas.

Santos; Costa e Granjeiro (2009) apontam que a maioria dos casos de abusos sexuais ocorrem no seio familiar, e os casos mais comuns de abuso sexual são praticados pelos pais biológicos das vítimas e, em segundo, pelos padrastos. Tratase de um tipo de Violência Intrafamiliar que, de acordo com Araújo (2002), acontece na família envolvendo pessoas que residem ou não no mesmo local, mas que não é restrita somente à família, e sim, envolve sujeitos de comum convívio no mesmo espaço doméstico, tendo ou não laços de parentesco. Deste modo, pode-se afirmar que há um risco de as pessoas idealizarem determinado estereótipo para tais abusadores, não atentando-se a que, mesmo que sejam trabalhadores, "pais de família", pagadores de impostos, tenham um bom convívio social, sejam ricos, pessoas gentis e educadas ou que aparentemente eduque e cuide bem de seus filhos, isto não significa que tais pessoas não possam cometer abuso sexual, ainda que possuam uma conduta louvável perante a sociedade.

"A maioria dos pedófilos não apresenta antecedentes criminais e as pessoas de sua convivência o descrevem como trabalhador, religioso e cuidador zeloso de sua família" (COHEN; MANNARINO, 2000a; apud HABIGZANG et al., 2005, p.346). 
Além disso, agressores com estereótipos vistos socialmente como de bons cidadãos, podem provocar a acomodação das pessoas a não se atentarem aos cuidados de prevenção com crianças e adolescentes a respeito do abuso sexual, como também pode confundir no processo de suspeita e identificação desta violência. Outrossim, dependendo da relação que o agressor tem com a família, muitos dos casos não são denunciados. Por exemplo, uma mãe pode não denunciar seu esposo porque confia nele, não dando crédito à denúncia da criança ou adolescente porque não quer se afastar do conjugue ou porque depende do agressor para sustentar a família, dentre outras situações. Williams (2002) cita outro aspecto importante, que é o fato de ainda atualmente a violência sexual ser considerada como um tabu, e muitas vezes a própria vítima é estigmatizada e frequentemente apresenta sentimento de culpa ou vergonha; este, dentre outros, é um dos motivos para a não denúncia por parte de pessoas que fazem ou não parte da família da vítima.

Entretanto, Habigzang et al. (2005) apresenta o mapeamento de fatores de risco para abuso sexual intrafamiliar que foram identificados nos processos jurídicos do Ministério Público do Rio Grande do Sul - Brasil, analisando 71 expedientes que apresentam o perfil dos agressores; uma das características marcantes foi que a maioria dos agressores estavam desocupados ou com trabalho eventual. "O desemprego é um fator de risco para a violência intrafamiliar, uma vez que pode gerar estresse e conflito entre os membros da família" (HABIGZANG et al., 2005, p. 345). Além disso, o cuidador acaba ficando como responsável pela criança ou adolescente por maior parte do tempo, o que proporciona mais oportunidades da ocorrência de abusos sexuais. Outras características encontradas na maioria dos abusadores deste estudo são: baixo nível de escolaridade, casados ou vivendo maritalmente, usuários de álcool ou drogas, entre outras coisas. É relevante salientar que estas características foram encontradas em uma porcentagem dos casos estudados e, ainda que sejam bastante comuns, existem muitos abusadores que não apresentam nenhuma dessas características. Deste modo, é importante que os adultos se atentem e busquem informações que aumentem seu 
conhecimento sobre o assunto e assim consigam criar uma rede de proteção à criança e ao adolescente, podendo não somente identificar, mas prevenir, evitando o abuso sexual aconteça.

Para Brino e Willians (2005), o abuso sexual infantil pode ser prevenido por meio de ações que podem ser divididas em três níveis de prevenção. O primeiro nível é o primário, que objetiva eliminar ou reduzir os fatores sociais, ambientais e culturais que sejam propícios para os atos de agressão. Deste modo, pode-se promover ações que visam a capacitação de profissionais e as demais pessoas envolvidas de forma direta com a criança como, por exemplo, professores. Ademais, pode-se promover ações junto à população de risco, promovendo a educação de crianças sobre os riscos do abuso sexual.

Santos e Ippolito (2009) defendem que a educação sexual é a melhor maneira de prevenção, e que apesar de pertencer ao adulto responsável pela educação da criança e do adolescente, a responsabilidade de protegê-los contra o abuso sexual, um programa de educação continuada é capaz de preparar as crianças e adolescentes a se defenderem desta violência.

Outro meio de prevenção citado pelos autores é a inclusão social da criança tida como "diferente", ou rejeitadas pelos grupos. "Atrás da subjugação da criança ao abuso sexual sofrido em casa ou na vizinhança ou seu silêncio diante dele, normalmente existe uma busca de aceitação e afeto de um ente querido" (SANTOS; IPPOLITO, 2009, p.128). Deste modo, muitas das crianças que foram vítimas de abuso sexual possuíam baixo nível de estima própria, e geralmente cresceram isoladamente na própria casa e na comunidade em que vive, vendo-se como diferente das outras e não tendo orientações sexuais fundamentais.

Visando ainda a prevenção, Santos e Ippolito (2009) sugerem às escolas que estas promovam a sensibilização dos familiares responsáveis pela educação das crianças e dos adolescentes, utilizando a criatividade de seus educadores para o trabalho com essas famílias, estimulando-as e ensinando-as a fortalecer a criança e 
adolescente contra o abuso sexual; manterem um relacionamento de confiança com a criança; dedicarem tempo a ela, e ouvir abertamente o que a criança tem a dizer, não banalizando em casos em que a criança abusada "quebra o silêncio", achando que ela deve estar inventando os fatos e; construírem uma rede de social de suporte entre os familiares no trabalho de proteger a criança em momentos que o membro da família que é responsável pela educação dos mais novos tenha que ausentar-se do Lar. Os autores afirmam que: "A maioria dos atos de abuso intra e extrafamiliar ocorre quando a criança se encontra a sós com jovens e adultos na própria casa ou na casa de conhecidos" (SANTOS; IPPOLITO, 2009, p.129).

O segundo enfoque, segundo Brino e Willians (2005), é o secundário, que objetiva detectar precocemente crianças em situação de risco, impedindo, assim, a repetição dos atos de violência, trabalhando com o intuito de reduzir o stress ocasionado pelo processo no sistema legal pelo qual a criança passa, tendo em vista que a postura dos profissionais que trabalham com a criança pode amenizar ou acabar por produzir danos psicológicos na vítima. O terceiro e último enfoque apresentado pelos autores é o terciário; este possui como objetivo o acompanhamento da vítima bem como do agressor, por profissionais capacitados, a fim de obstar ou amenizar prejuízos ocasionados pelo abuso sexual, assim como possíveis sequelas em longo prazo.

Considerando a importância de se trabalhar com a prevenção do abuso sexual, atuando-se em conjunto com os responsáveis e/ou com a criança, é possível planejar intervenções visando a prevenção primária e secundária. As mães, por exemplo, podem ter um papel decisivo na proteção contra esta violência. "Quando esses são incapazes de reconhecer a ocorrência de abuso sexual e de proteção, a criança pode se tornar mais vulnerável ao abuso" (BRINO; WILLIANS, 2005, p.176). Daí a importância de se buscar por meios de informar mães acerca do abuso sexual para que se tornem capazes de proteger a criança da ocorrência desse tipo de agressão, e a escola pode ser um lugar estratégico para tal ação, já que é uma instituição capaz de promover intervenções aproveitando o contato direto com pais, crianças e adolescentes.

RC: 96433

Disponível em: https://www.nucleodoconhecimento.com.br/psicologia/aspectoshistoricos 
Brino e Willians (2005) reforçam a ideia de que capacitar crianças e mães a reconhecerem sinais de que o abuso sexual esteja acontecendo pode ser uma ação que efetivamente interrompa a ocorrência da mencionada violência. Esta intervenção direcionada à criança abarcaria o reconhecimento de sinais de aproximação de um agressor, como também o reconhecimento de comportamentos sexuais inadequados. Às mães, a ação envolveria reconhecer comportamentos indicadores do abuso sucedido. Quando a proposta da ação é a detecção de crianças e adolescentes em situação de risco, rompendo com os atos violentos ou suas repetições, intervindo em casos já confirmados e trabalhando na prevenção de sequelas possíveis, esta perspectiva se enquadra na prevenção secundária ou até terciária.

Além da prevenção, é de fundamental importância que tenhamos conhecimento sobre o que fazer caso o abuso sexual já tenha ocorrido. É necessário saber denunciar, cuidar da vítima dando o amparo necessário e encaminhando à tratamentos especializados (BRINO; WILLIAMS, 2003b, p.2).

Uma das maneiras de denunciar, como mostra o site da UNICEF[7], é entrando em contato com o Conselho Tutelar, considerando que é atribuição dos conselheiros zelar pela garantia dos direitos da criança e do adolescente. Ao receberem a notificação, cabe a esses profissionais a análise da procedência de cada caso, fazendo visitas à família. Caso o fato seja confirmado, o Conselho deve encaminhar a situação ao Ministério Público.

Outro meio de denúncia apontado pela UNICEF é contatando as Varas da Infância e da Juventude, no caso de municípios que não possuam Conselho Tutelar. As denúncias podem ser feitas também nas Delegacias de Proteção à Criança e ao adolescente e nas Delegacias da Mulher. Há também um aplicativo para smartphones e tablets chamado Proteja Brasil, que mostra os telefones e a localização da instituição especializada mais próxima da do denunciante. Além disso o aplicativo oferece auxílio em caso de dúvidas sobre o tipo de violência. 
O Disque 100 - Direitos Humanos é um canal em que "as denúncias poderão ser anônimas ou, quando solicitado pelo denunciante, é garantido o sigilo da fonte das informações" (BRASIL, s/d). Desse modo qualquer pessoa pode fazer a denúncia sem que seja identificada. Denunciar não é sinônimo de acusar, já que é o profissional especializado quem fará a investigação dos fatos. Sendo assim, é importante enfatizar que não é necessário ter certeza de que o abuso sexual tenha ocorrido para que a denúncia seja feita. Trata-se de um ato de comprometimento com a segurança e bem-estar da criança e do adolescente, além de que a omissão é um ato tão grave quanto o próprio abuso sexual. O ECA, em um Parágrafo único do art. 70-B, determina que

São igualmente responsáveis pela comunicação de que trata este artigo, as pessoas encarregadas, por razão de cargo, função, ofício, ministério, profissão ou ocupação, do cuidado, assistência ou guarda de crianças e adolescentes, punível, na forma deste Estatuto, o injustificado retardamento ou omissão, culposos ou dolosos (BRASIL, 1990).

O Estatuto, então, enfatiza a responsabilidade das pessoas, que de alguma forma estão envolvidas na vida da criança e do adolescente, de fazer a denúncia em caso de violação dos direitos destes. Isto reafirma a obrigação da delação de um ato tão grave quanto o abuso sexual, ainda que se trate de uma suspeita.

Diante desses apontamentos, entende-se que o abuso sexual se trata de um assunto grave, de história ampla, que perpassa por discussões políticas, de valores culturais (que se modificam de acordo com as regiões do mundo, e com o momento histórico), e por questões de saúde física, psicológica e social, podendo comprometer gravemente a vida de muitas crianças e adolescentes.

\section{CONSIDERAÇÕES FINAIS}

Este artigo teve por objetivo abordar os aspectos históricos do abuso sexual, perpassando pela legislação brasileira e explorando as complexidades do assunto até mesmo com relação à definição e nomenclatura. 
Viu-se que a criança e o adolescente nem sempre foram considerados como seres humanos que necessitam de respeito e cuidados específicos e que, ao longo da história, diversos tipos de violências foram cometidos contra esse público sem que houvesse punição aos agressores, nem mesmo a atenção do poder público para a proteção dessas pessoas.

Diante de diversos casos de crueldade e negligência, leis foram sendo instituídas a favor da criança e do adolescente e, no Brasil, o ECA marca o estabelecimento de diversos direitos, prevendo a proteção de menores de idade, e requerendo dos adultos a responsabilidade de cuidar deles.

Destarte, o abuso sexual é um dos fenômenos que ganhou a atenção do Estado e, atualmente, medidas de proteção contra tal violência foram sendo estabelecidas. Estudos mostram os prejuízos biopsicossociais que esta agressão pode provocar à vítima e à sua família, como também os mecanismos que envolvem a prática do abuso sexual, permitindo que estratégias de prevenção sejam tomadas e que agressores de diferentes perfis sejam identificados e punidos.

Não obstante, sabe-se que falta ainda conhecimento da população geral sobre o assunto, inclusive de familiares e instituições que são responsáveis pela proteção da criança e do adolescente como a escola, por exemplo. Ademais, a falta de esclarecimento sobre este fenômeno é um fator que corrobora para que esta violência continue sendo reproduzida. Há, então, a necessidade de mais pesquisas e intervenções que proporcionem à população cada vez mais informações sobre o tema, provocando a sensibilização para o engajamento de todos em favor da garantia dos direitos da criança e do adolescente, potencializando, assim, o combate contra o abuso sexual.

\section{REFERÊNCIAS}

ADED et al. Abuso sexual em crianças e adolescentes: revisão de 100 anos de literatura. Revista de Psiquiatria Clínica 33 (4); 204-213, 2006. [online]. Disponível 
em: <http://www.hcnet.usp.br/ipq/revista/vol33/n4/204.html>. Acesso em: 27 de mai. de 2015.

ARAÚJO, M. de F. Violência e Abuso Sexual na Família. Psicologia em Estudo, Maringá, v. 7, n. 2, p. 3-11, jul./dez. 2002. [online]. Disponível em: $<$ http://www.scielo.br/scielo.php?pid=S1413-

$73722002000200002 \&$ script=sci_arttext>. Acesso em: 09 de set. de 2015.

AZAMBUJA, M. R. F. de. Violência sexual intrafamiliar: é possível proteger a criança? Revista Virtual Textos \& Contextos, nº 5, nov. 2006. [online]. Disponível em: <http://revistaseletronicas.pucrs.br/ojs/index.php/fass/article/view/1022>. Acesso em 09 de set. de 2015.

BRASIL. Ministério da Saúde. Notificação de maus-tratos contra crianças e adolescentes pelos profissionais de saúde. Secretaria de Assistência à Saúde. Série A. Normas e Manuais Técnicos; n. 167. Brasília-DF, 2002. [online]. Disponível em: <http://bvsms.saude.gov.br/bvs/publicacoes/notificacao_maustratos_criancas_adoles centes.pdf>. Acesso em: 27 de mai. de 2015.

Site: Conselho Nacional de Saúde. 18 de maio - Dia nacional de combate ao abuso e exploração sexual de crianças e adolescentes. s/d. Disponível em <http://conselho.saude.gov.br/ultimas_noticias/2009/15_mai_caesca.htm>. Acesso em: 06 de jun. de 2016.

Constituição (1988). Constituição da República Federativa do Brasil: promulgada em 5 de outubro de 1988. [online]. Disponível em: <http://www.planalto.gov.br/ccivil_03/Constituicao/Constituicao.htm>. Acesso em: 07 de out. de 2016.

. Estatuto da Criança e Adolescente. Lei 8.069, de 13 de julho de 1990. Brasília, 1990. [online]. Disponível em: <http://www.planalto.gov.br/ccivil_03/LEIS/L8069.htm>. Acesso em 09 de set. de 2015.

RC: 96433

Disponível em: https://www.nucleodoconhecimento.com.br/psicologia/aspectoshistoricos 
. Superior Tribunal de Justiça. Súmula 593. O crime de estupro de vulnerável se configura com a conjunção carnal ou prática de ato libidinoso com menor de 14 anos, sendo irrelevante eventual consentimento da vítima para a prática do ato, sua experiência sexual anterior ou existência de relacionamento amoroso com o agente. Terceira Seção. Julgado em 25/10/2017. DJe 06/11/2017. Disponível em <https://www.stj.jus.br/sites/portalp/Inicio>. Acesso em: 14 de abr. de 2021.

BRINO, R. F.; WILLIAMS, L. C. Capacitação do educador acerca do abuso sexual infantile. Interação em Psicologia, 7(02), p. 1-10, 2003b. [online]. Disponível em:<file:///C:/Users/Usuario/Downloads/3218-6348-1-PB\%20(1).pdf>. Acesso em 13 de abr. de 2016.

Prevenção primária, secundária e terciária do abuso sexual infantil. In:Sobre o comportamento e cognição- Expondo a variabilidade. Org. GUILHARDI, H. J.; AGUIRRE, N. C. de. p.174-181, 2005.

DECLARAÇÃO UNIVERSAL DOS DIREITOS HUMANOS, Adotada e proclamada pela resolução 217 A (III) da Assembléia Geral das Nações Unidas em 10 de dezembro de 1948. Representação da UNESCO no Brasil. Brasília, 1998. [online] Disponível em: <http://unesdoc.unesco.org/images/0013/001394/139423por.pdf>. Acesso em: 05 de jun. de 2016.

FALEIROS, E. T. S; CAMPOS, J. de O. C. Repensando os conceitos de violência, abuso e exploração sexual de crianças e de adolescentes. CECRIA / MJ-SEDH-DCA / FBB / UNICEF. Brasília, 2000. [online] Disponível em: $<$ http://escca.luizaugustopassos.com.br/wpcontent/uploads/2011/02/livro_repensando_os_conceitos_eva_publicacoeshttpwww.mpes_.gov_.branexoscentros_apoioarquivos1.pdf1.pdf>. Acesso em: 02 de jun. de 2016.

GUERRA, A. M. A. et al. Crianças e adolescentes têm direitos: conheça o Sistema de Garantia dos Direitos e saiba como participar. Org. GRACIANI, M. S. S. et al. $1^{\underline{a}}$ ed. São Paulo: CONDECA: Manufatura de ideias, 2013.

RC: 96433

Disponível em: https://www.nucleodoconhecimento.com.br/psicologia/aspectoshistoricos 
HABIGZANG, L. F. et al. Abuso sexual infantil e dinâmica familiar: aspectos observados em processos jurídicos. Psicologia: Teoria e Pesquisa, Brasília, v. 21, n.3, p.341-348, $2005 . \quad$ Disponível em:<http://www.scielo.br/scielo.php?script=sci_arttext\&pid=S0102-

$37722005000300011 \&$ Ing=en\&nrm=iso >. Acesso em: 07 de set. de 2016.

HABIGZANG, L. F.; RAMOS, M. da S.; KOLLER, S. H. A Revelação de Abuso Sexual: As Medidas Adotadas pela Rede de Apoio. Psicologia: Teoria e Pesquisa Out-Dez 2011, Vol. 27 n. 4, pp. 467-473. [online]. Disponível em: <http://www.scielo.br/pdf/ptp/v27n4/10.pdf>. Acesso em: 09 de set. de 2015.

HARMS, M. (org.) Vade Mecum RT. [Equipe RT]. 12 ed. revista, atualizada e ampliada. São Paulo: Editora Revista dos Tribunais, 2016. ISBN 978-85-203-6714-8.

INOUE, S. R. V.; RISTUM, M. Violência sexual: caracterização e análise de casos revelados na escola. Estudos de Psicologia (Campinas) [online]. 2008, vol.25, n.1, pp. 11-21. ISSN 1982-0275. Disponível em: <http://www.scielo.br/scielo.php?pid=S0103166X2008000100002\&script=sci_abstract\&tIng=pt>. Acesso em: 27 de mai. de 2015.

LEMOS, F. C. S. O Estatuto da Criança e do Adolescente no Brasil atual. Revista Psicologia Política, São Paulo, v. 8, n. 15, p. 93-106, jun. 2008. Disponível em $<$ http://pepsic.bvsalud.org/scielo.php?script=sci_arttext\&pid=S1519549X2008000100007\&lng=pt\&nrm=iso >. Acesso em:08 de jun. de 2016.

MINAYO, M. C. S. O significado social e para a saúde da violência contra crianças e adolescentes. In:WESTPHAL, M. F. (org). Violência e criança. São Paulo: Edusp, 2002.

OLIVEIRA, I. S. de. Trajetória Histórica do Abuso Sexual Contra Criança e Adolescente. UniCEUB: Brasília. 2006. Professor-orientador: Dr. Maurício Neubern. 
PADILHA, M. da G. S. Abuso sexual contra crianças e adolescentes: considerações sobre os fatores antecedentes e sua importância na prevenção. In: GUILHARDI, H. J.; AGUIRRE, N. C. (Orgs.) Sobre Comportamento e Cognição: Expondo a variabilidade. Santo André: ESETec, 2002, v.10, p. 209 a 220.

PAPALIA, D.; OLDS, S.W.; FELDMAN, R. D. Desenvolvimento Humano. 8 ed.Porto Alegre: Artmed, 2006.

PRADO, M. do C. de A.; CARNEIRO, T. F. Abuso sexual e traumatismo psíquico. Interações, São Paulo, v. 10, n. 20, p. 11-34, dez. 2005. [online] Disponível em:<http://pepsic.bvsalud.org/scielo.php?script=sci_arttext\&pid=S1413$29072005000200002 \&$ lng=pt\&nrm=iso>. Acesso em: 23 de abr. de 2016.

SANTOS. B. R. dos; IPPOLITO, R - Childhood Brasil. O papel da escola no enfrentamento da violência sexual. In: LAVARELLO, F. (Coord). A defesa de crianças e adolescentes vítimas de violências sexuais. São Paulo: Cromosete, 2009, p. $125-130$.

SANTOS, V. A. dos; COSTA, L. F.; GRANJEIRO, I. A. C. L. Intervenção no abuso sexual intrafamiliar: ingerência invasiva ou proteção devida? Psico, Porto Alegre, PUCRS, v. 40, n. 4, pp. 516-524, out./dez. 2009. [online]. Disponível em: <http://revistaseletronicas.pucrs.br/ojs/index.php/revistapsico/article/view/4009>. Acesso em: 09 de set. de 2015.

SERAFIM, A. de P. et al. Dados demográficos, psicológicos e comportamentais de crianças e adolescentes vítimas de abuso sexual. Revista de Psiquiatria Clínica, São Paulo, v. 38, n. 4, p. 143-147, 2011. [online]. Disponível em: <http://www.scielo.br/scielo.php?script=sci_arttext\&pid=S010160832011000400006>. Acesso em: 09 de set. de 2015.

UNICEF. Situação mundial da infância (edição especial): celebrando 20 anos da Convenção sobre os Direitos da Criança. UNICEF, 2009. [online] Disponível em: 
$<$ http://www.unicef.org/brazil/pt/sowc_20anosCDC.pdf>. Acesso em: 03 de jun. de 2016.

VEGA, L. B. da S.; PALUDO, S. dos S. Exploração sexual e rede de proteção na perspectiva da vítima. Arquivos Brasileiros de Psicologia, Rio de Janeiro, v. 67, n. 2, p. 47-60, $2015 . \quad$ Disponível em <http://pepsic.bvsalud.org/scielo.php?script=sci_arttext\&pid=S1809$52672015000200005 \&$ Ing=pt\&nrm=iso $>$. Acesso em: 29 de maio de 2016.

WAISELFISZ, J. J. Atendimento por Violência No SUS. In: Mapa da Violência 2012: Crianças e Adolescentes do Brasil. 1 ed. Rio de Janeiro: CEBELA, 2012. p.62-73.

WILLIAMS, L. C. A. Abuso sexual infantil. In: GUILHARDI, H. J.; AGUIRRE, N. C. (Orgs.). Sobre Comportamento e Cognição: Expondo a variabilidade. Santo André: ESETec, 2002, v.10, p.155-164.

\section{APÊNDICE - REFERÊNCIA NOTA DE RODAPÉ}

3. Dados obtidos em https://agenciapatriciagalvao.org.br/violencia/violenciasexual/tres-criancas-ou-adolescentes-sao-abusadas-sexualmente-no-brasil-a-cadahora/

4. Site Portal Brasil: < http://www.brasil.gov.br/cidadania-e-justica/2015/07/em-1927o-brasil-ganhou-oprimeiro-codigo-de-menores>.

5. Site DUDH: < http://www.dudh.org.br/declaracao/>.

6. Site CRAMI: <http://www.cramicampinas.org.br

7. Site UNICEF: <http://www.unicef.org/brazil/pt/activities_10790.htm>.

Enviado: Maio, 2021.

Aprovado: Setembro, 2021.

RC: 96433

Disponível em: https://www.nucleodoconhecimento.com.br/psicologia/aspectoshistoricos 